\title{
Assessing Undergraduate Students' Class Attendance and Academic Performance in a Psychology Course at the University of Technology, Jamaica
}

\author{
Henry Lewis, Cynthia Onyefulu* \\ Faculty of Education and Liberal Studies, University of Technology, Jamaica \\ Email: hjlewis@utech.edu.jm, *conyefulu@utech.edu.jm
}

How to cite this paper: Lewis, H. and Onyefulu, C. (2020) Assessing Undergraduate Students' Class Attendance and Academic Performance in a Psychology Course at the University of Technology, Jamaica. Open Access Library Journal, 7: e6605. https://doi.org/10.4236/oalib.1106605

Received: July 12,2020

Accepted: October 24, 2020

Published: October 27, 2020

Copyright $\odot 2020$ by author(s) and Open Access Library Inc.

This work is licensed under the Creative Commons Attribution International License (CC BY 4.0).

http://creativecommons.org/licenses/by/4.0/

(c) (i) Open Access

\begin{abstract}
The main purpose of this study was to examine the relationship between class attendance and undergraduate students' academic performance in the introductory psychology course at the University of Technology, Jamaica. Three research questions guided the study. An ex-post-facto design was used in the study. The secondary data used were academic performance scores and attendance register of 83 first-year ( 28 males \& 55 females) undergraduate students who were enrolled in an introduction to psychology course during the 2017/2018 academic year. No sampling was done. The results showed a weak positive relationship between attendance and mid-semester test $(r=0.177)$. There was no relationship between attendance and final score $(r=0.085)$, and there was a strong positive relationship between the mid-semester test and final scores $(r=0.714)$. The results also showed that there were statistically significant differences between the mid-semester test and final performance, $(F(3,79)=$ $3.819, p=0.026)$ and $(F(3,79)=5.201, p=0.008)$, respectively. A recommendation made for undergraduate students to be adequately informed about the likely impact attendance may have on their academic performance.
\end{abstract}

\section{Subject Areas}

Education and Social Sciences

\section{Keywords}

Academic Performance, Attendance, Attendance Policy, Undergraduate Students

\section{Introduction}

Over the years, attendance to lecture-based classes and student performance at 
the tertiary level has grabbed the attention of several researchers from different disciplines, which includes but not limited to medical education [1] [2] [3] [4] [5], computer science [6], and extensive field studies [7].

Recently, to get more accurate results on attendance and student academic performance, some researchers have started using Wifi and Bluetooth technology to track student attendance and to make a prediction on students' academic performance [7] [8] [9]. No matter the method used by the researchers, the topic continues to generate increase.

With the evidence that absenteeism is associated with poor academic performance, several colleges and universities have on their webpage an attendance policy and students are encouraged to attend classes [10]. The policies are designed to reduce absenteeism and to make a difference in student class attendance [11]. Although this may be seen as a good move, some students are not in favour of mandatory attendance [12].

Despite the attendance policy controversy, the findings from the different studies have shown mixed results. For instance, a large number of studies reported a significant moderate positive relationship between class attendance and academic performance [2] [5] [13]. In contrast, others have shown little or no correlation between the two variables [1] [3] [7]. Notwithstanding, it is still essential to continue to investigate this topic because not all fields have been studied, and there is room to add to the literature.

\subsection{Background of the Study}

In the University of Technology (UTech), Jamaica, both undergraduate and postgraduate programmes are offered in three colleges and five faculties. The Office of Teaching and Learning is responsible for ensuring quality in the teaching and learning process (UTech, Jamaica, Student Handbook [14]). The courses taken by the undergraduate students are classified under the following groups, pre-requisite, core general education, and electives. The introduction to psychology course used in this study falls under the general education category. The general education courses are designed to provide foundation knowledge to enhance students' learning experience (UTech, Jamaica, Undergraduate Student Enrolment Guide [15]).

The introduction to psychology course is a 45-credit hour course for some first-year undergraduate students in programmes such as nursing, medical technology, child and adolescent development/disability studies, dietetics and nutrition, information technology, and sport sciences/sport management. This course is developed and delivered by lecturers in the School of Humanities and Social Sciences in the Faculty of Education and Liberal Studies and is designed to create an awareness of the science of psychology, the human behaviour, lifespan development, motivation theories, as well as social psychology.

The course contains 11 units, and each unit is taught for three contacts (face-to-face) hours. Every week, the students enrolled in the course would have 
one mass lecture and two hours tutorial for 13 instructional weeks. Four groups of students whose scores were used in this study attended their tutorial classes on the following days and time, Monday (11 am to $1 \mathrm{pm}$ ), Tuesdays ( 8 am to 10 am), Fridays ( 8 am to $10 \mathrm{am}$ ), and Fridays (10 am to 12 noon). It is during these tutorial classes that attendance is taken. This practice is in line with the statement made in the UTech, Jamaica Student Handbook [14], which states that class register indicating students in attendance should be signed for tutorial and laboratories. The students are assessed through course work only. These include two individual tests, a group presentation, and a final paper.

\subsection{Statement of the Problem}

The university position on class attendance has changed over the years. For instance, in the University of Technology, Jamaica, Student Handbook [16], it was stated that "class attendance is not compulsory and no penalty will be imposed for failure to do so" (p. 57). By the 2007-2008 academic year, its position was that class attendance is the "best opportunity for optimum academic performance" (University of Technology, Jamaica, Student Handbook [17] (p. 54). Currently, the university position is that "students should attend all scheduled classes consistently, in order to ensure the best opportunity for optimum academic performance" [14] (p. 69).

Over the years, two researchers in the university have conducted studies on student attendance ad academic performance. Due to these changes in positions concerning class attendance, Onyefulu [18] conducted a study with teacher-education students to ascertain the relationship between class attendance and academic performance in a compulsory education course. During this study, the university had not made attendance compulsory. Five years later, Murray-Pusey [19] conducted another study; that examined class attendance and academic performance of undergraduate students in two nursing courses in the same university. In both studies, the authors found a relationship between class attendance and academic performance of the students. These studies strengthened the position of the university for all lecturers to implement attendance policy by keeping accurate attendance record for their classes.

Since the introduction to psychology is a compulsory course for some first-year students, and not all students attend classes regularly, the authors of the present study wanted to know if attendance and academic performance had any relationship. Therefore, the study was designed for this reason.

\subsection{Purpose of the Study}

The purpose of the study is three folds: First, to examine the relationship between class attendance and the undergraduate students' academic performance in the introductory psychology course; Second, to compare their academic performance with the day and time of the course; Third, to ascertain if there is any sex difference in the academic performance of the students. 


\subsection{Research Questions}

The questions answered in this study were:

1) Is there a significant difference between the undergraduate students' class attendance and their academic performance in the introduction to psychology course?

2) To what extent do the students' academic performance differ by day and time the course is offered?

3) To what extent do the students' academic performance differ by sex (male $\&$ female)?

\section{Literature Review}

Students' class attendance plays a vital role in academic performance in higher education [2] [20]. As a result, a considerable body of research studies exists on class attendance ad academic performance. However, most of the studies are beyond 10 years. Attempts were made in this study to include some of the ones that were published after 2000 due to their relevance.

\subsection{Students' Class Attendance and Academic Performance}

Several articles published in the last four decades on students' class attendance and the impact it has on their academic performance have revealed mixed results. For instance, in a study conducted by Paisey and Paisey [21] in a Scottish university, they examined 81 students' non-attendance to an accounting module and the effect it had on the students' academic performance. Their study revealed a positive relationship between attendance and academic achievement. Paisey and Paisey [21] also identified, among other things, factors such as working and timing of the class to affect academic performance and attendance to classes. The study Chen and Lin [22] also found a positive relationship between the same variables when they did a randomized experiment in Taiwan. They reported an average attendance of $91 \%$ among the students in an economics class. In yet another study done in Taiwan, Chou and Kuo [23] also found a positive relationship. Among other things, Jaykaran, Yadaav, Chavda, and Kantharia [24], were of the view that factors which may affect students' performance in pharmacology exam are attendance, the medium of schooling and marks in the first year (p. 124). However, Fadelelmoula [2], who studied 75 respiratory care students in Saudi Arabia, revealed that although attendance and final exam results showed a positive relationship, it lacked statistical significance. At the same time, the study by Wambuguh and Yonn-Brown [25] revealed a weak positive correlation between a quiz and final examination performance among 1294 students.

On the issue of time of the day, attendance, and academic performance, Ray [26] investigated the effect of the hour of day learning occurred in an all-male college $(n=408)$ enrolled in Business Administration programme. The results showed, among other things, that students tended to skip classes more in the af- 
ternoon than in the morning, and that being absent from class negatively impacted on students' academic performance. According to Ray [26], there was a "negative relationship between absences (ABS) and academic performance (AP)" (pp. 8-9).

In another study by Kantartzi1, Allen, Lodhi, Grier, and Kassem [27] who studied 621 students in three classes in a university in North Carolina; they indicated that class time was responsible for absenteeism and that students preferred 9:30 am to 10:30 am as well as 4:00 to 6:00 pm classes.

\subsection{Students' Class Attendance and Academic Performance and Gender}

Some studies on class attendance, performance and gender have also shown mixed results. For instance, the study by Kantartzil et al. [27] never found any significant difference with gender and attendance students among university students in North Carolina. They also stated that "gender does not seem to affect grades significantly" [27] (p. 18). Furthermore, the study by Niraula and Sharma [28] did not show any significant difference in gender and MBBS students' academic performance in Nepal. These studies were different from the conclusion made by Jaykaran et al. [24]. They stated that [g]ender is considered to be contributing to academic performance in undergraduate and postgraduate programmes (p. 124). A study by Cortright, Lujan, Cox, and DiCarlo [29] at East Carolina University, showed that regular attendance among female students an exercise physiology course impacted their examination performance than male students.

Finally, on the issue of class time and academic performance Randler and Frech [30] who examined the relationship between class time (morning \& evening) and final exams of 132 university students concluded that the time of the classes (am \& pm) impacted students' learning and grades. They found that students who were classified as "morning-oriented" were more likely to display better academic achievement [29].

\section{Method}

\subsection{Research Design}

An ex-post-facto design was used to examine the relationship of university students' performance in an introductory psychology course and their class attendance, as well as to compare their academic performance with the day and time of the course.

\subsection{Population and Sample}

The participants whose data were used in this study were 83 first-year students who were enrolled in the psychology course from across the university in 2017/2018 academic year. The set of scores used were conveniently selected by the lecturer who taught the students. No sampling was done as all the scores of the 
students who were registered to take the course with the lecturer were used in the study.

Of the 83 students, 28 (34\%) were males, and 55 (66\%) were females. It should be noted that the number used in this study did not represent all students' scores who registered for the course during that academic year.

\subsection{Data Collection}

Secondary data were gathered from the attendance register, grade sheet, and course timetable. Attendance was measured by the overall tutorial attendance during the 13 weeks of the semester. Students' performance in the course was assessed by their mid-semester (test) scores and the final score at the end of the semester. The time and day the tutorial classes were held, was obtained from the timetable.

The course was delivered twice a week with an hour mass lecture and a two-hour tutorial. The attendance was only taken for the tutorial classes because it was easy to monitor due to the small size $(n \leq 25)$. This is because attendance record was difficult to keep for the mass lecture due to large student numbers.

\subsection{Data Analysis}

Each student was assigned a code number and beside each code, the percentage of attendance, mid-semester and final scores, and the day and time of class were recorded. Data were entered into the Statistical Package for Social Sciences (SPSS), version 23, and analyzed using percentage, mean, standard deviation, independent $t$-test, and one-way analysis of variance.

\subsection{Study Limitations}

Two limitations were noted in the study. First, not all the students during the academic year were used. Only those students taught by one of the researchers were used in the study. Therefore, the sample did not represent the population of students who took the course that academic year. Second, the sample size was not big enough. Due to these limitations, the results could not be generalized to the population of first-year students in the university who took the course that year.

\subsection{Ethical Considerations}

The study was non-intrusive and did not require any direct interaction with the participants. This is because it involved the use of secondary information, which did not affect the welfare of the students. The Ethics Committee granted clearance before data were used in the study. The students' name and identification numbers were kept private, and confidentiality was observed.

\section{Results}

The findings are presented according to the research questions that guided the 
study.

\subsection{Research Question One: Is There a Significant Difference between the Undergraduate Students' Class Attendance and Their Academic Performance in the Introduction to Psychology Course?}

The student attendance (percentage score), test and final scores in psychology were used to find the answer to this research question. The Pearson product-moment relationship $(r)$ test was conducted to determine the association between the variables (see Table 1).

There was a weak positive relationship between attendance $(M=89, S D=$ 12.2) and mid-semester test $(M=60, S D=11.6), r=0.177, p=0.110, n=83$. There was no relationship between attendance $(M=89, S D=12.2)$ and final score $(M=68, S D=7.02), r=0.085, p=0.446, n=83$. However, there was a strong positive relationship between mid-semester test score $(M=60, S D=11.6)$ and final score $(M=68, S D=7.02), r=0.714, p=0.001, n=83$ (see Figure 1 for the scatter plot).

\subsection{Research Question Two: To What Extent Do the Students' Academic Performance Differ by Day and Time of the Course Is Offered?}

The tutorial classes were three days a week at various times, as presented in $\mathrm{Ta}$ ble 2. The data were analyzed using one-way analysis of variance test (ANOVA). The Levene test was conducted, and the results showed that the requirement of homogeneity of variance was met and one-way analysis of variance was computed (see Table 2). The results of the descriptive statistics are presented (see Table 3).

There was a statistically significant difference between groups for the midsemester test and final performance, as shown by the ANOVA test. For the mid-

Table 1. Pearson product-moment relationship.

\begin{tabular}{lcccc}
\hline & & Attendance & Final Score & Test Score \\
\hline \multirow{3}{*}{ Attendance } & Pearson Correlation & 1 & 0.085 & 0.177 \\
& Sig. (2-tailed) & $n$ & 0.446 & 0.110 \\
& Pearson Correlation & 0.085 & 83 & 83 \\
Final Score & Sig. (2-tailed) & 0.446 & 1 & $0.714^{* *}$ \\
& $n$ & 83 & 83 & 0.000 \\
& Pearson Correlation & 0.177 & $0.714^{* *}$ & 83 \\
Test Score & Sig. (2-tailed) & 0.110 & 0.001 & 1 \\
& $n$ & 83 & 83 & 83 \\
\hline
\end{tabular}

${ }^{* *}$ Correlation is significant at the 0.01 level (2-tailed). 


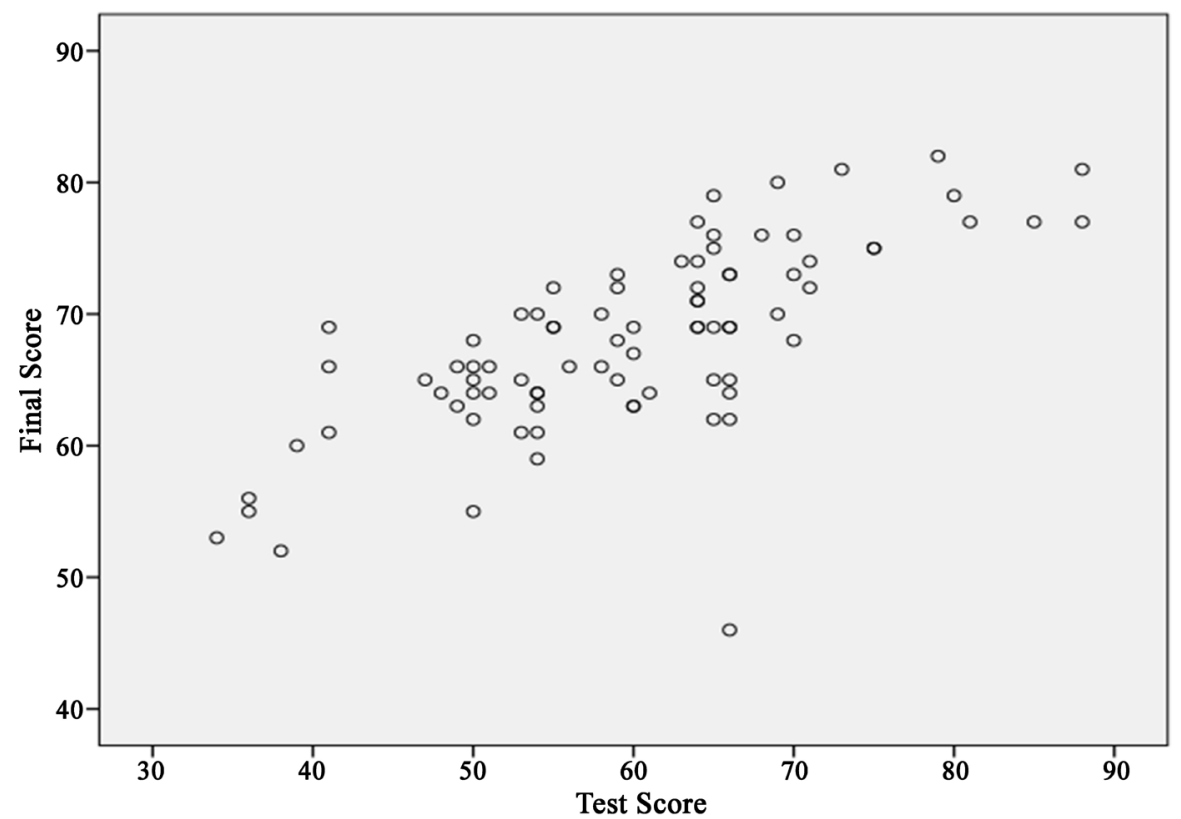

Figure 1. Scatter plot for test and final assessment.

Table 2. Test of homogeneity of variances.

\begin{tabular}{ccccc}
\hline Assessment & Levene Statistic & $\boldsymbol{d f 1}$ & $\boldsymbol{d f 2}$ & Sig. \\
\hline Final & 0.903 & 2 & 80 & 0.409 \\
Test & 1.816 & 2 & 80 & 0.169 \\
\hline
\end{tabular}

Table 3. Descriptive statistics for day, time and performance.

\begin{tabular}{|c|c|c|c|c|c|}
\hline Day & Time & Assessment & $(n)$ & Mean & $S D$ \\
\hline \multirow[t]{2}{*}{ Monday } & $11 \mathrm{am}-1 \mathrm{pm}$ & Final & 24 & 72 & 6.59 \\
\hline & & Test & 24 & 65 & 9.69 \\
\hline \multirow[t]{2}{*}{ Tuesday } & $8 \mathrm{am}-10 \mathrm{am}$ & Final & 24 & 66 & 6.19 \\
\hline & & Test & 24 & 57 & 10.30 \\
\hline \multirow[t]{2}{*}{ Fridays } & $8 \mathrm{am}-10 \mathrm{am}$ & Final & 19 & 66 & 8.11 \\
\hline & & Test & 19 & 57 & 13.6 \\
\hline \multirow[t]{2}{*}{ Fridays } & 10 am to 12 noon & Final & 16 & 68 & 5.53 \\
\hline & & Test & 16 & 59 & 11.63 \\
\hline
\end{tabular}

semester test, $(F(3,79)=3.819, p=0.026)$. A Tukey post hoc comparison test showed that the performance for the Monday (11 am - $1 \mathrm{pm})$ and Tuesday ( $8 \mathrm{am}$ - $10 \mathrm{am}$ ) groups were statistically significant, as well as the Monday (11 am - 1 pm) and Friday (8 am - 10 am).

The ANOVA for the final score was $(F(3,79)=5.201, p=0.008)$. A Tukey post hoc comparison test showed that the performance for the Monday (11 am $1 \mathrm{pm})$ and Tuesday ( $8 \mathrm{am}-10 \mathrm{am}$ ) groups were statistically significant, as well as Monday (11 am - $1 \mathrm{pm})$ and Friday (8 am - $10 \mathrm{am})$. The mean difference was 
significant at the 0.05 level.

\subsection{Research Question Three: To What Extent Do the Students' Academic Performance Differ by Sex (Male \& Female)?}

The independent $t$-test was computed after conforming the assumption of equal variances $(p>0.05)$. See Table 4 for the mean and standard deviation values for both groups.

The mean scores did not differ for the two (male \& female) groups in the two assessments; final score, $t(81)=-1.743, p=0.085$, and test score, $t(81)=-0.165$, $p=0.869$.

\section{Discussion}

Concerning research question one, although the mean score for attendance ( $M=$ 89), was higher by 29 points when compared with the mean score of the midsemester test, there was a positive (weak) relationship between attendance and mid-semester test scores obtained by the undergraduate students $(r=0.177, p=$ 0.11). According to Schober, Boer, and Schwarte [31] and Akoglu [32], this type of relationship are described as "weak". The weak relationship notwithstanding, the results suggested that attendance to classes made a difference in students' academic performance in the mid-semester test.

There was a 21-point difference in the mean score for attendance and final examination; there was no relationship between attendance and final exam $(r=$ $0.085, p=0.446)$. This result was similar to the finding of the study done by Fadelelmoula [2], in which the "relationship between attendance and final exam results lacked statistical significance" (p. 48). In contrast, Deane and Murphy [32] found a positive correlation between attendance and overall students' examination score. Chou and You [23], and Lukkarinena, Koivukangasa, and Seppäläa [13] also found a positive relationship between attendance and performance in their studies.

Nonetheless, there was a positive relationship between mid-semester test score and final score $(r=0.714, p=0.001)$. By using the guide published by Schober, Boer, and Schwarte [30] and Akoglu [31], this relationship is "strong".

This is similar to the results of Wambuguh and Yonn-Brown [24] who also found a significant positive relationship between a quiz and final examination performance.

Regarding research question two, there was a statistically significant difference

Table 4. Descriptive statistics for male and female students' performance.

\begin{tabular}{ccccc}
\hline \multirow{2}{*}{ Scores } & \multicolumn{2}{c}{ Male $(n=28)$} & \multicolumn{2}{c}{ Female $(n=55)$} \\
\cline { 2 - 5 } & Mean & $S D$ & Mean & $S D$ \\
\hline Final & 66 & 8.05 & 69 & 6.29 \\
Test & 60 & 11.81 & 60 & 11.54 \\
\hline
\end{tabular}


between groups who had their tutorial at different times of the day, $(F(3,79)=$ $3.842, p=0.015)$. A Tukey post hoc comparison test showed that the performance for the Monday (11 am - $1 \mathrm{pm})$ and Tuesday (8 am - $10 \mathrm{am})$ groups were statistically significant, as well as the Monday (11 am - $1 \mathrm{pm})$ and Friday (8 am $10 \mathrm{am}$ ). The mean difference was significant at the 0.05 level. At the University of Technology, Jamaica, morning classes are scheduled from 8 am to $11 \mathrm{am}$, afternoon from 12 noon to $4 \mathrm{pm}$, and evening classes were from $5 \mathrm{pm}$ to $9 \mathrm{pm}$ (UTech, Jamaica, Undergraduate Student Enrollment Guide [15]).

The present findings showed that overall, the students who had tutorial class Monday (11 am - 1 pm) had 91\% attendance and performed slightly better than the other groups. This is consistent with the findings of Paisey and Paisey [21], who found the timing of the class affected academic performance and attendance to classes. Kantartzi1, Allen, Lodhi, Grier, and Kassem [25] also found that class time affected attendance to classes because certain times are convenient for students to attend classes. Randler and Frech [29] concluded that time of the classes (am \& pm) impacted students' learning and grades, and also Ray [25] was of the view that class attendance and time-of-day affected students' academic performance.

Regarding research question three the mean scores did not differ for the two (male \& female) groups in the two assessments; final score, $t(81)=-1.743, p=$ 0.085 , and test score, $t(81)=-0.165, p=0.0 .869$. There was a three-point mean score difference between the test and final scores which showed a marginal improvement for the final assessment score for the female group. This was in accordance with the study by Kantartzi1, Allen, Lodhi, Grier, and Kassem [26], which did not find any significant difference between gender and attendance. Jaykaran, Yadaav, Chavda, and Kantharia [20] considered gender as a contributing factor to academic performance. This is dissimilar to the findings of Cortright, Lujan, Cox, and DiCarlo [28] who found that regular attendance among female students impacted on their examination performance than male students.

\section{Conclusions}

The main objectives of this study were to examine the relationship between class attendance and the undergraduate students' academic performance in the introductory psychology course; to compare the students' academic performance with the day and time of the course; and to ascertain if there was any sex difference in the academic performance of the students. There was a weak positive relationship between attendance and mid-semester test. There was no relationship between attendance and final score, and there was a strong positive relationship between the mid-semester test and final scores. The results also showed that there were statistical significant differences between mid-semester test and final performance.

Although this study found a weak positive correlation between class attendance and academic performance, the result is still significant, as it supports the 
university stands on mandatory attendance. The undergraduate students should be adequately informed about the likely impact it may have on their academic performance. The present results will help the lecturers and the university administrators to understand better attendance and student's academic performance among the undergraduate students in the university.

\section{Recommendations}

Based on the results, we recommend that the undergraduate students should be adequately informed about the likely impact attendance may have on their academic performance. We also advocate for future studies, that larger sample size should be used, and consideration to be given to other attendance factors in the future.

\section{Conflicts of Interest}

No potential conflict of interest was reported by the authors.

\section{References}

[1] Eisen, D.B., Schupp, C.W., Isseroff, R.R., Ibrahimi, O.A., Ledo, L. and Armstrong, A.W. (2015) Does Class Attendance Matter? Results from a Second-Year Medical School Dermatology Cohort Study. International Journal of Dermatology, 54, 807-816. https://doi.org/10.1111/ijd.12816

[2] Fadelelmoula, T. (2018) The Impact of Class Attendance on Student Performance. International Research Journal of Medicine and Medical Sciences, 6, 47-49.

https://doi.org/10.30918/IRJMMS.62.18.021

[3] Kauffman, C.A., Derazin, M., Asmar, A. and Kibble, J.D. (2018) Relationship between Classroom Attendance and Examination Performance in a Second-Year Medical Pathophysiology Class. Advances in Physiology Education, 42, 593-598. https://doi.org/10.1152/advan.00123.2018

[4] Khan, Y.L., Lodhi, S.K., Bhatti, S. and Ali, W. (2020) Does Absenteeism Affect Academic Performance among Undergraduate Medical Students? Evidence from "Rashid Latif Medical College (RLMC)". Advances in Medical Education and Practice, 10, 999-1008. https://doi.org/10.2147/AMEP.S226255

[5] Nowreen, N., Chowdhary, S. and Hameed, R. (2019) Impact of Class Attendance on Academic Performance in the Subject of Physiology. National Journal of Physiology, Pharmacy and Pharmacology, 9, 524-526. https://doi.org/10.5455/njppp.2019.9.0309826032019

[6] Pudaruth, S., Nagowah, L., Sungkur, R. and Chiniah, A. (2013) The Effect of Class Attendance on the Performance of Computer Science Students. 2nd International Conference on Machine Learning and Computer Science (IMLCS 2013), Kuala Lumpur, 25-26 August 2013, 9-16.

[7] Kassarnig, V., Bjerre-Nielsen, A., Mones, E., Lehmann, S. and Lassen, D.D. (2017) Class Attendance, Peer Similarity, and Academic Performance in a Large Field Study. PLoS ONE, 12, e0187078. https://doi.org/10.1371/journal.pone.0187078

[8] Wang, R., Harari, G., Hao, P., Zhou, X. and Campbell, A.T. (2015) SmartGPA: How Smartphones Can Assess and Predict Academic Performance of College Students. ACM Conference on Ubiquitous Computing, Osaka, 7-11 September 2015, 295-306. https://doi.org/10.1145/2750858.2804251 
[9] Zhou, M., Ma, M., Zhang, Y., Sui, K., Pei, D. and Moscibroda, T. (2016) EDUM: Classroom Education Measurements via Large-Scale WiFi Networks. In: Proceedings of the 2016 ACM International Joint Conference on Pervasive and Ubiquitous Computing, ACM Press, New York, 316-327. https://doi.org/10.1145/2971648.2971657

[10] Foldnes, N. (2017) The Impact of Class Attendance on Student Learning in a Flipped Classroom. Nordic Journal of Digital Literacy, 12, 8-18.

https://doi.org/10.18261/issn.1891-943x-2017-01-02-02

[11] Self, S. (2012) Studying Absenteeism in Principles of Macroeconomics: Do Attendance Policies Make a Difference? Journal of Economic Education, 43, 223-234. https://doi.org/10.1080/00220485.2012.686382

[12] Verbeeten, M.J. and van Hoof, H.B. (2007) Mandatory Attendance Policy and Motivation among Hospitality Management Students. Journal of Hospitality \& Tourism Education, 19, 28-37. https://doi.org/10.1080/10963758.2007.10696880

[13] Lukkarinen, A., Koivukangas, P. and Seppälä, T. (2016) Relationship between Class Attendance and Student Performance. Procedia-Social and Behavioral Sciences, 228, 341-347. https://doi.org/10.1016/j.sbspro.2016.07.051

[14] University of Technology, Jamaica (2019) Welcome to the University of Technology, Jamaica: Student Handbook 2019-2020.

http://www.utechjamaica.edu.jm/publications/undergradhandbook

[15] University of Technology, Jamaica (2017) Undergraduate Student Enrollment Guide: 2017-2018. http://www.utechjamaica.edu.jm/enrolment

[16] University of Technology, Jamaica (2001) Student Handbook 2001-2002.

[17] University of Technology, Jamaica (2007) Student Handbook 2007-2008.

[18] Onyefulu, C. (2009) Students' Class Attendance and Academic Performance in an Education Course at the University of Technology, Jamaica. In: Ezenne, A., Ed., Higher Education in the Caribbean: Research, Challenges and Prospects, C \& A Publishers Ltd., Tanzania, 335-363.

[19] Pusey-Murray, A. (2017) Attendance and Performance of Undergraduate Students in Two Nursing Courses in a University in Jamaica. In: Onyefulu, C., Ed., Advancing Education in the Caribbean and Africa. Science and Education Development Institute, Akure, 1-165.

[20] Jaykaran, Y.P., Chavda, N. and Kantharia, N.D. (2011) Factors Associated with Performance of Second Year Student in Pharmacology Examinations. Journal of Pharmacology \& Pharmacotherapeutics, 2, 123-125.

https://doi.org/10.4103/0976-500X.81911

[21] Paisey, C. and Paisey, N.J. (2004) Student Attendance in an Accounting Module Reasons for Non-Attendance and the Effect on Academic Performance at a Scottish University. Accounting Education, 13, 3953.

https://doi.org/10.1080/0963928042000310788

[22] Chen, J. and Lin, T.-F. (2008) Class Attendance and Exam Performance: A Randomized Experiment. Journal of Economic Education, 39, 213-227. https://doi.org/10.3200/JECE.39.3.213-227

[23] Chou, P.T.-M. and Yuo, Y.-M. (2012) Examining Factors Relating to Classroom Attendance and Performance. Journal of Studies in Education, 2, 193-204. https://doi.org/10.5296/jse.v2i2.1564

[24] Wambuguh, O. and Yonn-Brown, T. (2013) Regular Lecture Quizzes Scores as Predictors of Final Examination Performance: A Test of Hypothesis Using Logistic Re- 
gression Analysis. International Journal for the Scholarship of Teaching and Learning, 7, Article 7. https://doi.org/10.20429/ijsotl.2013.070107

[25] Ray, M. (2009) Does the Hour of Day Affect Learning Statistics? https://doi.org/10.2139/ssrn.1464365

[26] Kantartzi1, S.K., Allen, S., Lodhi, K., Grier, R.L. and Kassem, A. (2010) Study of Factors Affecting Students' Performance in three Science Classes: General Biology, Botany, and Microbiology at Fayetteville State University. KBM Journal of Science Education, 1, 13-18. https://doi.org/10.5147/kbmjse.2010.0014

[27] Niraula, S. and Sharma, S. (2006) Critical Analysis of Performance of Medical Students. Education Health, 19, 5-13. https://doi.org/10.1080/13576280500534578

[28] Cortright, R.N., Lujan, H.L., Cox, J.H. and DiCarlo, S.E. (2011) Does Sex (Female versus Male) Influence the Impact of Class Attendance on Examination Performance? Advances Physiology Education, 35, 416-420.

https://doi.org/10.1152/advan.00021.2011

[29] Randler, C. and Frech, D. (2006) Correlation between Morningness-Eveningness and Final School Leaving Exams. Biological Rhythm Research, 37, 233-239.

https://doi.org/10.1080/09291010600645780

[30] Schober, P., Boer, C. and Schwarte, L.A. (2018) Correlation Coefficients: Appropriate Use and Interpretation. Anesthesia \& Analgesia, 126, 1763-1768.

https://doi.org/10.1213/ANE.0000000000002864

[31] Akoglu, H. (2018) User's Guide to Correlation Coefficients. Turkish Journal of Emergency Medicine, 18, 91-93. https://doi.org/10.1016/j.tjem.2018.08.001

[32] Deane, R. and Murphy, D. (2013) Student Attendance and Academic Performance in Undergraduate Obstetrics/Gynecology Clinical Rotations. JAMA: The Journal of the American Medical Association, 310, 2282-2288.

https://doi.org/10.1001/jama.2013.282228 